Cite this: Nanoscale, 2013, 5, 1499

\section{Encapsulation of $\mathrm{Mo}_{2} \mathrm{C}$ in $\mathrm{MoS}_{2}$ inorganic fullerene-like nanoparticles and nanotubes}

\author{
Inna Wiesel, ${ }^{a}$ Ronit Popovitz-Biro ${ }^{\mathrm{b}}$ and Reshef Tenne*a
}

Received 26th November 2012

Accepted 19th December 2012

DOI: $10.1039 / c 2 n r 33828 a$

www.rsc.org/nanoscale

$\mathrm{Mo}_{2} \mathrm{C}$ nanoparticles encapsulated within $\mathrm{MoS}_{2}$ inorganic fullerenelike nanoparticles and nanotubes were produced by carbothermal reaction at $1200-1300{ }^{\circ} \mathrm{C}$ inside a vertical induction furnace. The particles were analyzed using various electron microscopy techniques and complementary methods.

Closed-cage nanostructures of carbon and their inorganic counterparts possess an inner void which could be filled with various materials. ${ }^{1-5}$ This filling can alter the properties of the encaging nanoparticles as well as of the filling material, stabilize phases not stable otherwise and lead to observation of interesting phenomena.

Encapsulation of metal carbides within carbon nanoclusters was demonstrated many times using the arc-discharge technique..$^{6-9}$ Transition metal dichalcogenides $\mathrm{MX}_{2}(\mathrm{M}=\mathrm{W}$, Mo; $\mathrm{X}=\mathrm{S}, \mathrm{Se})$ are inorganic layered compounds that can be synthesized, akin to carbon, in onion-like and nanotubular forms (termed IF and INT, respectively). ${ }^{10}$ The large scale synthesis of IF and INT of $\mathrm{WS}_{2}$ is based on the conversion of tungsten oxide nanoparticles into their respective sulfides. In this case, encapsulation of the corresponding metal oxide naturally occurs within those structures during the synthetic process; ${ }^{11}$ WC nanoparticles encapsulated within $\mathrm{WS}_{2}$ were synthesized as well by high-temperature sulfidization. ${ }^{12}$ In this communication, we report the synthesis of $\mathrm{Mo}_{2} \mathrm{C}$ nanosized crystals confined within $\mathrm{MoS}_{2}$ closed-cage nanoparticles and nanotubes.

Many of the transition metal carbides are superconductors; ${ }^{13}$ in particular molybdenum carbide is superconducting in its various phases. ${ }^{14}$ The high-temperature phase of $\mathrm{Mo}_{2} \mathrm{C}(\beta$ $\mathrm{Mo}_{2} \mathrm{C}$ ) forms at temperatures above $1220{ }^{\circ} \mathrm{C} .{ }^{15}$ It has a closely packed hexagonal structure, belonging to the $P 6_{3} / m m c$ space

\footnotetext{
${ }^{a}$ Department of Materials and Interfaces, Weizmann Institute of Science, Rehovot 76100, Israel.E-mail: reshef.tenne@weizmann.ac.il

${ }^{b}$ Department of Chemical Research Support, Electron Microscopy Unit, Weizmann Institute of Science, Rehovot 76100, Israel
}

group (ICDD PDF \#00-035-0787) and has a superconducting transition temperature $\left(T_{\mathrm{c}}\right)$ in the range of $5.1-7.2 \mathrm{~K} .{ }^{14}$ The study of 1D superconductors is attracting considerable interest. ${ }^{16}$ Previously, it was suggested that intrinsic thermal ${ }^{17}$ and quantum ${ }^{18}$ fluctuations play a major role in the $1 \mathrm{D}$ limit and lead to lowering of $T_{\mathrm{c}}$. In the same context, $\mathrm{WS}_{2}$ nanotubes were proven in the past to be good templates for superconducting hybrid nanowire fabrication. ${ }^{19}$ Synthesis of nanoscale $\mathrm{Mo}_{2} \mathrm{C}$ encapsulated by $\mathrm{MoS}_{2}$ may provide an opportunity for more elaborate investigation of the low-dimensional superconductivity phenomena.

IF-MoS ${ }_{2}$ and IF-WS ${ }_{2}$ nanoparticles were shown to exhibit superior lubricating properties when added to a variety of lubricating fluids and the latter were recently commercialized for critical applications. Having a hard carbide encapsulated by a lubricating sulfide shell outside may prove advantageous for some applications, for example in composites with improved strength and reduced friction. In addition, both $\mathrm{Mo}_{2} \mathrm{C}$ and $\mathrm{MoS}_{2}$ are well-established catalysts for various forms of hydrotreatment (hydrodesulfurization, hydrodenitrogenation, and hydrogenation). ${ }^{20,21}$ Nano-encapsulation may enhance the catalytic activity as well as the stability of the catalyst.

The synthesis was carried out in a home-built vertical induction furnace used for high-temperature synthesis in a protected atmosphere. The schematics of the system are shown in Fig. 1. The reaction chamber consists of a quartz tube capped on both ends with water-cooled air-tight stainless steel flanges. Flow of nitrogen gas was obtained through stainless steel tubes welded into those flanges. The cylindrical graphite susceptor is heated from outside the chamber by the highfrequency generator. A graphite crucible with the precursor material $\left(\mathrm{MoS}_{2}, 99 \%\right.$, Alfa Aesar) was positioned inside the central space of the graphite heater. The graphite crucible along with the graphite susceptor acts as a source of carbon for the carbothermal reaction which leads to the formation of $\mathrm{Mo}_{2} \mathrm{C}$. The substrate (perforated Mo foil $0.025 \mathrm{~mm}$ thick, $99.95 \%$, Alfa Aesar) is supported above the precursor crucible by graphite spacers. The substrates were cleaned by sonication 


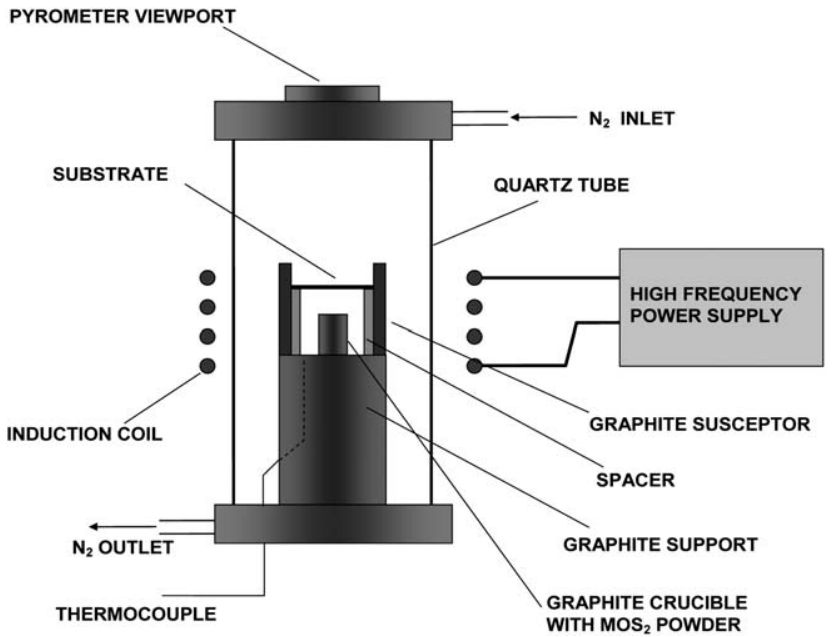

Fig. 1 Schematics of the induction furnace set-up.

in acetone for $10 \mathrm{~min}$ and air-dried. The surfaces of the Mo substrates were shown to have a $5 \mathrm{~nm}$ film of native oxide with a mixed $\mathrm{MoO}_{2}-\mathrm{MoO}_{3}$ composition by XPS. Prior to the reaction, the reactor was purged with $400 \mathrm{~cm}^{3} \mathrm{~min}^{-1}$ flow of nitrogen for 4 hours or alternatively with $100 \mathrm{~cm}^{3} \mathrm{~min}^{-1}$ overnight, in order to eliminate the traces of water and oxygen from the reaction chamber. The furnace in the described setup heats up to $1000{ }^{\circ} \mathrm{C}$ within a minute and then the heating progresses in a slower pace to reach a maximum temperature after $\sim 5 \mathrm{~min}$. The measured maximum temperature at the position of the precursor crucible, which was determined by pyrometric measurements, was $1305{ }^{\circ} \mathrm{C} \pm 50{ }^{\circ} \mathrm{C}$ (determined by heating the system with the crucible and the substrate removed from the line of sight of the pyrometer). However, the maximum temperature can reach $1650{ }^{\circ} \mathrm{C}$ and even higher, if the setup is adjusted (for example, in reactions with closed ampoules and different susceptor geometry, reaction temperatures as high as these were indeed realized). During the reaction, the temperature was monitored with a thermocouple inserted through the solid graphite support close to the position of the crucible. The temperature of the substrate could not be measured reliably due to large emissivity changes of the substrate in the course of the reaction (blackening of the initially shiny molybdenum foil), but is estimated to be $100-$ $200{ }^{\circ} \mathrm{C}$ less than the crucible by visual differences in color during heating. The reactions were carried out for 5-60 $\mathrm{min}$ under $100 \mathrm{~cm}^{3} \min ^{-1} \mathrm{~N}_{2}$ flow in a small overpressure of 2-4 millibar obtained by tuning the level of liquid ( $\mathrm{NaOH}$ solution) in a gas washing bottle connected downstream to the outlet of the system. After the reaction, the setup was allowed to cool to room temperature under the same $100 \mathrm{~cm}^{3} \mathrm{~min}^{-1}$ flow of nitrogen for $40 \mathrm{~min}$ and only then opened. A black product was formed on both sides of the Mo substrate. Samples for TEM analysis were prepared either by gently rubbing the TEM grid against the substrate, scratching the surface with a spatula and touching the spatula on the TEM grid or by sonicating the substrate (whole or piece-wise) in ethanol and dripping the resulting suspension on the grids.
Characterization of the product was performed mainly by using various electron microscopy techniques. The instruments which were used for the analysis include: a scanning electron microscope (Zeiss LEO Supra 55VP FEG SEM), a transmission electron microscope (Philips CM120 TEM), equipped with an EDS detector (EDAX); a high resolution transmission electron microscope with a field emission source (FEI Technai F30 HRTEM), equipped with a parallel electron energy loss spectroscopy (EELS) spectrometer (Gatan imaging filter-GIF (Gatan)). Complementary analyses were carried out by powder X-ray diffraction (XRD), X-ray photoelectron spectroscopy (XPS) and electron diffraction (ED).

XRD examination (Fig. 2) was carried out on the substrate coated with the product. As expected, the most prominent peaks belong to the metallic molybdenum of the substrate. The XRD pattern reveals the diffraction lines of hexagonal $\mathrm{Mo}_{2} \mathrm{C}$ and molybdenum subsulfide $\left(\mathrm{Mo}_{2.06} \mathrm{~S}_{3}\right)$. No evidence for $\mathrm{MoS}_{2}$ could be obtained from the XRD pattern. Presumably the molybdenum subsulfide forms by a reaction between the metallic molybdenum of the substrate and the $\mathrm{MoS}_{2}$ vapor.

SEM examination of the substrate surface revealed that the product consists of nanoparticles of assorted shapes in the size range of 10-1000 nm, as well as elongated structures of 1-7 $\mu \mathrm{m}$ long (Fig. 3). Much of the deposited material contains microscopic molybdenum carbide coated with a few layers of, usually discontinuous $\mathrm{MoS}_{2}$. Nonetheless, a minor amount of what appears to be nanoparticles and elongated nanostructures was clearly observed. To better understand the nature of these nanoparticles TEM analysis was used.

TEM examination of the nanostructures revealed their coreshell nature. Fig. 4 shows the TEM micrograph of a $\mathrm{MoS}_{2}$ closedcage nanoparticle encapsulating the molybdenum carbide single crystal core. On the top right, there is a line profile of the selected area. The measured spacing of $\sim 0.62 \mathrm{~nm}$ is consistent with (002) crystallographic planes of $\mathrm{MoS}_{2}$. The diffractogram of the particle shows the single-crystal pattern of hexagonal $\mathrm{Mo}_{2} \mathrm{C}$ $\left(\beta-\mathrm{Mo}_{2} \mathrm{C}, d_{100}=0.26 \mathrm{~nm}, d_{110}=0.15 \mathrm{~nm}\right)$ viewed down the $[001]$

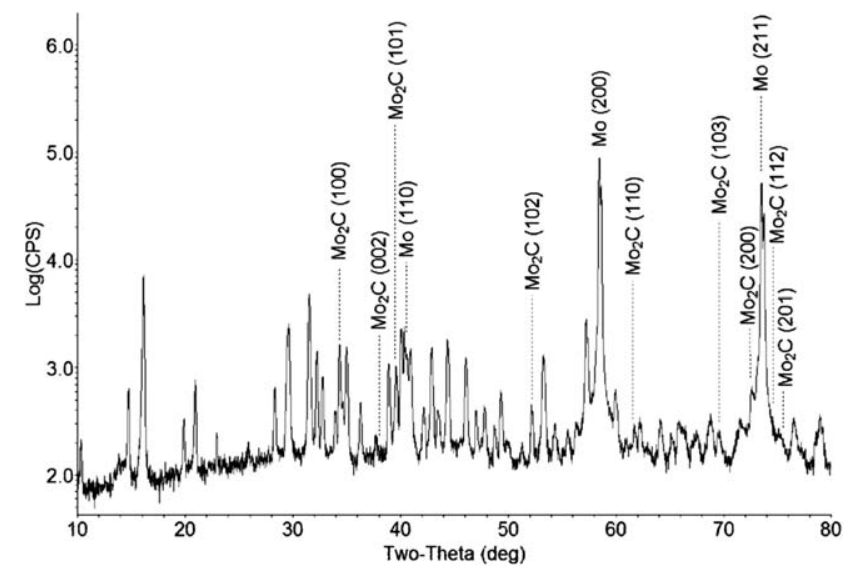

Fig. 2 X-ray diffraction pattern of the substrate with the reaction products (Cu$\mathrm{K} \alpha$ irradiation). Reflections of $\mathrm{Mo}$ and $\mathrm{Mo}_{2} \mathrm{C}$ are indexed, and the rest of the peaks (unindexed) belong to the $\mathrm{Mo}_{2.06} \mathrm{~S}_{3}$ phase. 


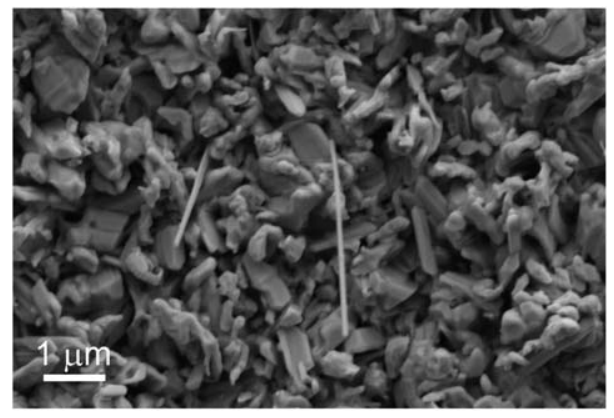

Fig. 3 SEM image of the reaction product.

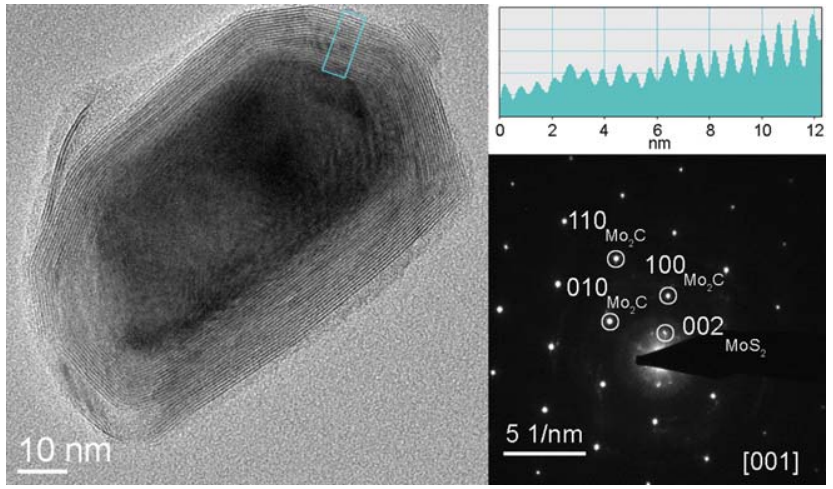

Fig. 4 TEM image of a $\mathrm{Mo}_{2} \mathrm{C} @ \mathrm{MoS}_{2}$ core-shell nanoparticle found on the substrate surface. The line profile of the selected area on the $\mathrm{MoS}_{2}$ coating is shown on the top right. The ED pattern (bottom right) clearly shows the reflections of the hexagonal pattern of the $\mathrm{Mo}_{2} \mathrm{C}$ core and the $\mathrm{MoS}_{2}$ layers coating the carbide core.

zone axis alongside with the 002 reflections $(d=0.62 \mathrm{~nm})$ associated with the crystal structure of the encapsulating $\mathrm{MoS}_{2}$.

EDS and EELS analysis confirmed the presence of Mo, S and $\mathrm{C}$, with sulfur to carbon ratios ranging from $1: 1$ to $1: 9$ on different nanoparticles.

The elongated nanostructures observed in the SEM were also analyzed by TEM. This analysis revealed that while some of the elongated nanoparticles were actually molybdenum sulfide or molybdenum carbide nanowhiskers, at least 30\% among these elongated nanostructures were actually made of $\mathrm{MoS}_{2}$ nanotubes encapsulating the $\mathrm{Mo}_{2} \mathrm{C}$ core. Fig. 5 shows several carbide-filled $\mathrm{MoS}_{2}$ nanotubes accompanied by several fullerene-like particles as obtained by energy filtered transmission electron microscopy (EFTEM) analysis performed in the F30 HRTEM. On top from left to right: sulfur map, carbon map and false-color image produced by overlapping the two maps. It is evident that sulfur is present only at the outer shells of the tubes and the interior material is carbon-rich. In Fig. 6 the HRTEM image of the continuous interface suggests epitaxial growth of $\mathrm{MoS}_{2}$ on $\mathrm{Mo}_{2} \mathrm{C}$ in limited number of interface zones of this core-shell nanotube. The similarity between the hexagonal lattices allows for the epitaxy to occur along more than one crystallographic direction, enabling the ultimate coverage of the carbide by the sulfide. In Fig. 6, the (100) spacing of $\operatorname{MoS}_{2}(d=0.273 \mathrm{~nm})$ coincides with the (100) spacing of

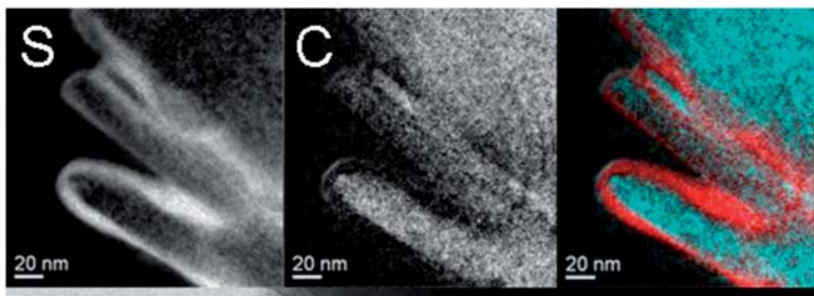

\section{zero loss}

\section{$20 \mathrm{~nm}$}

Fig. 5 Energy-filtered TEM analysis of the core-shell nanotubes. Top from left to right: sulfur map, carbon map and false-color image produced by overlapping the two maps (red - sulfur, blue - carbon), bottom: zero-loss image.

$\mathrm{Mo}_{2} \mathrm{C}(d=0.26 \mathrm{~nm})$, but similar seamless growth along other directions was observed as well (see for example Fig. 4 where such growth can be observed on at least three of the facets of the encapsulated crystal). The almost perfect interface coincidence may be of outmost importance when 1D superconductivity is considered.

Combining the information from the XRD pattern and the electron microscopy suggests that the molybdenum subsulfide $\left(\mathrm{Mo}_{2.06} \mathrm{~S}_{3}\right)$ is formed between the molybdenum substrate and
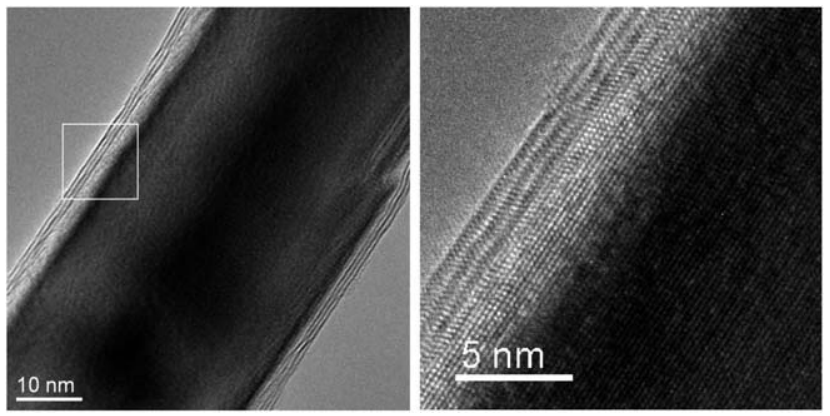

Fig. 6 HRTEM images of multiwall $\mathrm{MoS}_{2}$ nanotube coating a $\mathrm{Mo}_{2} \mathrm{C}$ core. Note the almost perfect matching between the two lattices at the interface in the enlargement image on the right. 
the encapsulated $\mathrm{MoS}_{2}-\mathrm{Mo}_{2} \mathrm{C}$ structures formed on the outer surface. This is further confirmed by differences in the TEM samples which were collected from the substrate surface using several different techniques. Using the technique of rubbing the TEM grid against the substrate surface resulted in more than $90 \%$ of the collected particles being molybdenum carbide partially or completely encapsulated by the $\mathrm{MoS}_{2}$ layers. In grids prepared from the sonicated specimen, a much more nonencapsulated sulfur-rich material was present. Whilst the rubbing affects only the surface, sonication releases material also from deeper layers of the coating, which are presumably rich in $\mathrm{Mo}_{2.06} \mathrm{~S}_{3}$.

The route to the formation of the encapsulated structures is suggested below. Upon heating, $\mathrm{MoS}_{2}$ is sublimed (sublimation onset circa $1050{ }^{\circ} \mathrm{C}$ (ref. 22)) and present in the gas phase in the volume of the heated zone. In addition, molybdenum trioxide and molybdenum dioxide from the substrate surface both decompose at temperatures above $1100{ }^{\circ} \mathrm{C}$ and a small amount of oxygen is released to the reaction volume. The oxygen can recombine with the carbon vapor (originated from the crucible and the susceptor) to form CO. In this temperature range, the $\mathrm{CO}_{2}$ formation process is subject to a less negative free energy change compared with CO formation, thus, CO predominates at high temperatures. CO, in its turn, reacts with $\mathrm{MoS}_{2}$ to give $\mathrm{Mo}_{2} \mathrm{C}:{ }^{23}$

$$
2 \mathrm{MoS}_{2}+6 \mathrm{CO} \rightarrow \mathrm{Mo}_{2} \mathrm{C}+4 \mathrm{COS}+\mathrm{CO}_{2}
$$

$\mathrm{Mo}_{2} \mathrm{C}$, having high melting temperature $\left(2687{ }^{\circ} \mathrm{C}\right.$ (ref. 24)), solidifies on the substrate and probably also as small clusters and whiskers in the gas phase. Upon cooling, $\mathrm{MoS}_{2}$ condenses to provide the concentric shells surrounding the $\mathrm{Mo}_{2} \mathrm{C}$ nanocrystals. Future studies will aim at increasing the yield of the core-shell nanotubes and nanoparticles. The increased yield will allow elucidating their physical properties and studying the superconducting behavior of the molybdenum carbide core, in particular.

In conclusion, $\mathrm{Mo}_{2} \mathrm{C}$ nanocrystals encapsulated in $\mathrm{MoS}_{2}$ nanoparticles and nanotubes were produced by high-temperature carbothermal reaction. The synthesis of this phase may open new possibilities in the investigation of properties of quasi-1D superconductors. In addition, this composite phase may prove advantageous in certain lubrication, structural and catalytic applications. The use of a high temperature induction furnace with a gas flow system opens up many opportunities for the synthesis of new nanomaterials, in particular from refractory metals such as $\mathrm{Nb}$, Ta and others.

\section{Acknowledgements}

The authors would like to thank WIS Engineering \& Instrumentation Branch and Dr Leonid Odnopozov for help with induction furnace construction, Dr Yishay (Isai) Feldman for XRD and Dr Tatyana Bendikov for XPS analyses. This research was supported by the ERC grant INTIF 226639; the Israel Science Foundation; The Harold Perlman Foundation and the
Irving and Azelle Waltcher Endowed Research Fund in honor of Prof. Moshe Levy. The Irving and Cherna Moskowitz Center for Nano and Bio-Nano Imaging is also acknowledged. RT is the Drake Family Chair in Nanotechnology and director of the Helen and Martin Kimmel Center for Nanoscale Science.

\section{References}

1 J. Sloan, J. Cook, M. L. H. Green, J. L. Hutchison and R. Tenne, J. Mater. Chem., 1997, 7, 1089-1095.

2 M. Monthioux, E. Flahaut and J. P. Cleuziou, J. Mater. Res., 2006, 21, 2774-2793.

3 S. F. Yang, F. P. Liu, C. B. Chen, M. Z. Jiao and T. Wei, Chem. Commun., 2011, 47, 11822-11839.

4 K. C. Hwang, J. Phys. D: Appl. Phys., 2010, 43, 374001/1374001/13.

5 S. Y. Hong, R. Kreizman, R. Rosentsveig, A. Zak, J. Sloan, A. N. Enyashin, G. Seifert, M. L. H. Green and R. Tenne, Eur. J. Inorg. Chem., 2010, 27, 4233-4243.

6 M. Terrones, W. K. Hsu, A. Schilder, H. Terrones, N. Grobert, J. P. Hare, Y. Q. Zhu, M. Schwoerer, K. Prassides, H. W. Kroto and D. R. M. Walton, Appl. Phys. A: Mater. Sci. Process., 1998, 66, 307-317.

7 Y. Saito, Carbon, 1995, 33, 979-988.

8 Y. Saito, T. Matsumoto and K. Nishikubo, J. Cryst. Growth, 1997, 172, 163-170.

9 Y. Saito, T. Masumoto and K. Nishikubo, Carbon, 1997, 35, 1757-1763.

10 R. Tenne, Nat. Nanotechnol., 2006, 1, 103-111.

11 Y. Feldman, G. L. Frey, M. Homyonfer, V. Lyakhovitskaya, L. Margulis, H. Cohen, G. Hodes, J. L. Hutchison and R. Tenne, J. Am. Chem. Soc., 1996, 118, 5362-5367.

12 A. Rothschild, J. Sloan, A. P. E. York, M. L. H. Green, J. L. Hutchison and R. Tenne, Chem. Commun., 1999, 4, 363-364.

13 G. F. Hardy and J. K. Hulm, Phys. Rev., 1954, 93, 1004-1016. 14 N. Morton, B. W. James, G. H. Wostenholm, D. G. Pomfret, M. R. Davies and J. L. Dykins, J. Less-Common Met., 1971, 25, 97-106.

15 T. Y. Velikanova, V. Z. Kublii and B. V. Khaenko, Sov. Powder Metall. Met. Ceram., 1988, 27, 891-896.

16 N. Giordano, Phys. B, 1994, 203, 460-466.

17 D. E. McCumber and B. I. Halperin, Phys. Rev. B: Solid State, 1970, 1, 1054-1070.

18 D. S. Golubev and A. D. Zaikin, Phys. Rev. B: Solid State, 2001, 64, 014504/1-014504/14.

19 A. Johansson, G. Sambandamurthy, D. Shahar, N. Jacobson and R. Tenne, Phys. Rev. Lett., 2005, 95, 116805/1-116805/4.

20 S. Eijsbouts, S. W. Mayo and K. Fujita, Appl. Catal. A, 2007, 322, 58-66.

21 E. Furimsky, Appl. Catal. A, 2003, 240, 1-28.

22 P. Cannon, Nature, 1959, 183, 1612-1613.

23 P. S. Rao, T. R. Mankhand and P. M. Prasad, Mater. Trans. JIM, 1996, 37, 239-244.

24 CRC Handbook of Chemistry and Physics, ed. D. R. Lide, CRC Press, Boca Raton, 84th edn, 2003-2004, section 4, p. 70, table entry number 1456 . 